\title{
Primary ovarian leiomyoma in a postmenopausal woman: A case report
}

\author{
Ilhan Sanverdi, ${ }^{1}$ Fisun Vural, ${ }^{2}$ Osman Temizkan, ${ }^{3}$ Orhan Temel, ${ }^{2}$ \\ Habibe Ayvaci, ${ }^{1}$ Pembegul Gunes ${ }^{4}$ \\ ${ }^{1}$ Obstetrics and Gynecology Department, Zeynep Kamil Maternity and Pediatric Research and Training Hospital, Istanbul, Turkey \\ 2Obstetrics and Gynecology Department, Haydarpasa Numune Training and Research Hospital, Istanbul, Turkey \\ ${ }^{3}$ Obstetrics and Gynecology Department, Sisli Hamidiye Etfal Training and Research Hospital, Istanbul, Turkey \\ ${ }^{4}$ Obstetrics and Gynecology Department, Haydarpasa Numune Training and Research Hospital, Istanbul, Turkey
}

\begin{abstract}
Leiomyomas are benign neoplasms that can develop wherever smooth muscle is present. Primary leiomyomas of the ovary originate from smooth muscle cells of ovarian tissue and are rare, solitary tumors. Approximately 70 cases have been reported. They usually present in premenopausal women. The present case is a report of left ovarian leiomyoma in a postmenopausal woman.
\end{abstract}

Keywords: Adnexal mass; leiomyoma; ovarian cancer; ovarian tumors; solid tumor.

$\mathrm{O}$ varian leiomyoma is very rare, solid tumor of the ovaries. It accounts for $0.5-1 \%$ of benign tumors of the ovary. They are benign in nature, but exact diagnosis requires histopathological evaluation and differentiation from other solitary tumors of the ovary, such as fibroma, thecoma, and sclerosing stromal tumor [1]. Approximately 70 cases have been reported. Most cases are asymptomatic, and $80 \%$ occur in premenopausal women [2]. The present case is that of a left ovarian leiomyoma: a solitary mass in the adnexal region and normal tumor markers in a woman who had undergone subtotal hysterectomy 16 years earlier. The objective is to discuss differential diagnosis of solid ovarian tumors.

\section{CASE REPORT}

A 52-year-old woman presented at the clinic with pelvic pain and floating of three months' duration. Subtotal hysterectomy had been performed 16 years earlier. There was no history of comorbidities or regular medication use (Gravidity: 1, Parity: 0, Abortion: 1). Transvaginal ultrasonography showed $25 \times 25 \mathrm{~mm}$ mass in the cervical region (cervix). There was solitary tumoral mass in the left adnexal area. Serum tumor markers were normal ( $\beta$ Human chorionic gonadotropin [hCG]: $<1 \mathrm{mIU} / \mathrm{mL}$, cancer antigen $[\mathrm{CA}]-125: 12 \mathrm{U} / \mathrm{mL}, \mathrm{CA}-15-3: 19 \mathrm{U} /$ $\mathrm{mL}, \mathrm{CA}-19-9: 5 \mathrm{U} / \mathrm{mL}$, Alpha fetoprotein [AFP]: $1.8 \mathrm{ug} / \mathrm{L}$, Carcinoembryonic antigen $[\mathrm{CEA}]: 1.2$ 


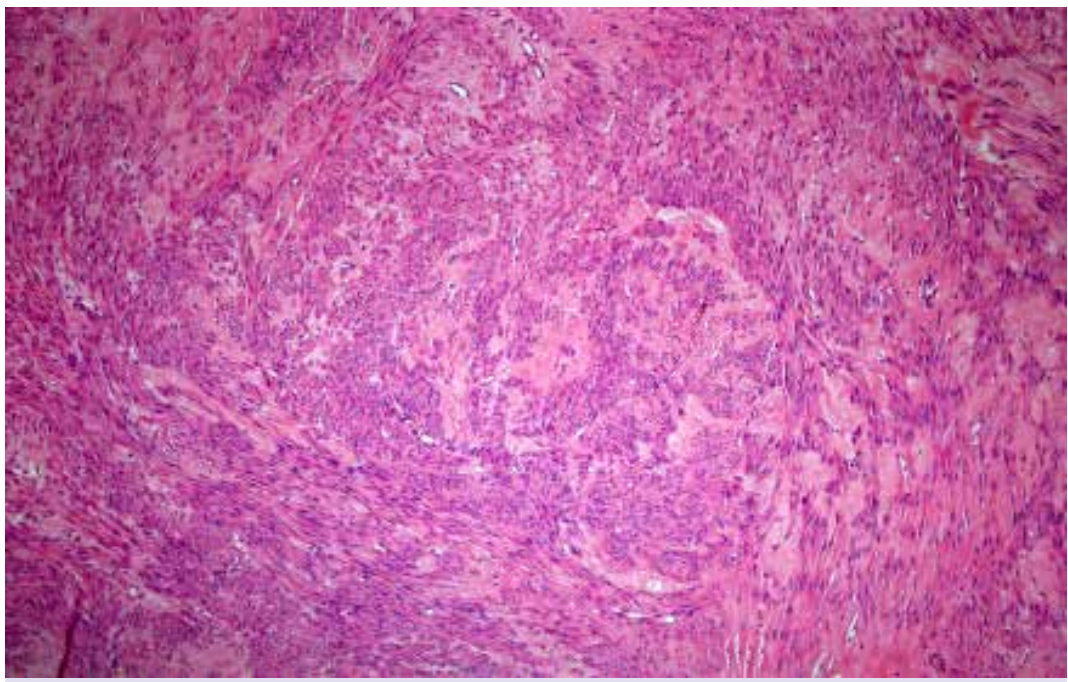

FIGURE 1. Whorled fascicles of tumoral proliferation (HEx100).

ng/mL, lactic dehydrogenase [LDH]: 193 IU/L). Complete blood count (CBC) results were: hemoglobin: $12.2 \mathrm{gr} / \mathrm{dL}$, hematocrit: $36 \%$, thrombocyte: $178,000 \mathrm{~mm}^{3}$, white blood count (WBC): 10700 $\mathrm{mm}^{3}$. Pelvic computed tomography (CT) showed solid, smooth contoured mass $(60 \times 50 \times 60 \mathrm{~mm})$ located in the left adnexal area. Bilateral oopherectomy was performed. Left site shows the solid mass, frozen section diagnosed leiomyoma.

Pathological Evaluation: The tumor was a whitish-gray, solid mass $(55 \times 55 \mathrm{~mm})$ with a smooth sur- face. Microscopic findings showed whorled interlacing fascicles of smooth muscle cells (leiomyoma). There was no cytologic atypia, necrosis, or mitosis. Microscopic view of leiomyoma $(\mathrm{HE} \times 100)$ can be seen in Figure 1. Smooth muscle cells with bundles of elongated cells and spindled nuclei $(\mathrm{HE} \times 200)$ can be seen in Figure 2.

\section{DISCUSSION}

Since the first report of primary ovarian leiomyomas

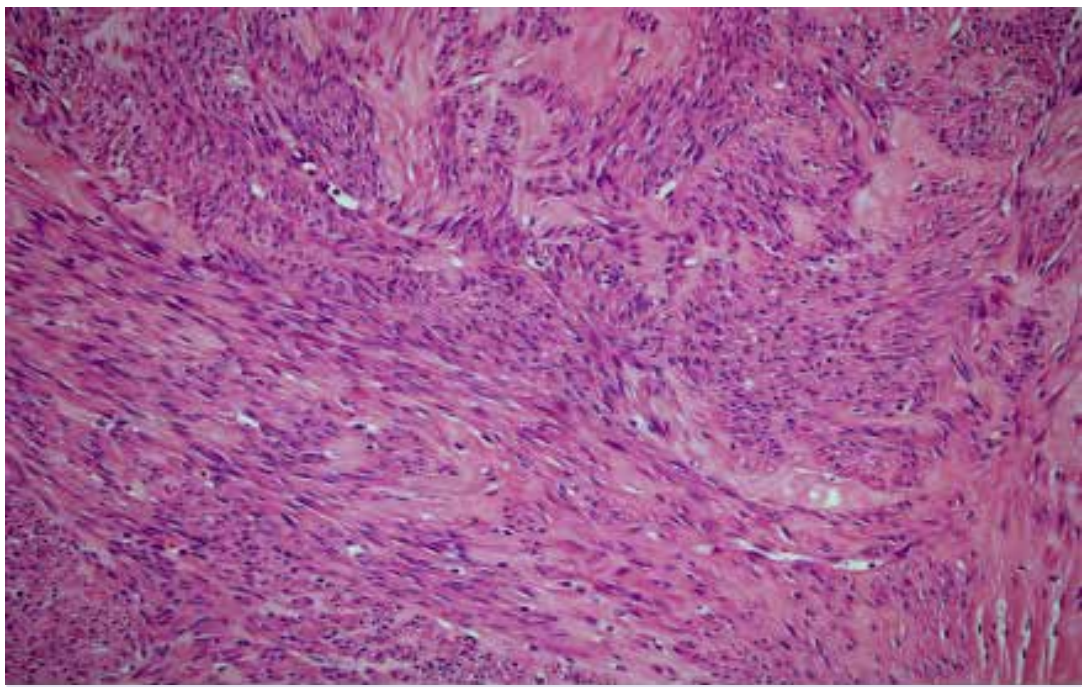

FIGURE 2. Smooth muscle cells with bundles of elongate cells and spindled nuclei (HEX200). 
in 1862 , few additional cases have been reported [2, $3]$. Data from prior reports indicate that primary ovarian tumors are benign, unilateral, asymptomatic, less than $3 \mathrm{~cm}$ in size, and occur in premenopausal women $[1,2]$. In this report, a case of a postmenopausal woman with ovarian leiomyoma is presented.

Leiomyomas are benign neoplasms, and can develop wherever smooth muscle is present. Primary leiomyomas often originate from smooth muscle cells in ovarian tissue. Most accepted theory for the histogenesis of leiomyoma in the ovary is growth of the tumor in smooth muscle cells of the ovarian ligament or smooth muscle fibers of the vascular wall or stroma $[3,4]$.

Ovarian leiomyomas are usually asymptomatic and are found either during routine physical examination or incidentally at surgery. Abdominal pain is a commonly encountered symptom, and rarely, some women present with elevated cancer antigen (CA)125, hydrothorax, and ascites [1,5-7]. The present patient presented at the clinic with pelvic pain.

Preoperative evaluation of ovarian solid tumors requires ultrasonography, tumor markers and MRI (magnetic resonance imaging). Ultrasonography shows solid mass isoechoic with myometrium, so it is difficult to distinguish from other solitary tumors or pedunculated myomas. MRI is often a useful adjunct to ultrasonography $[7,8]$. Preoperative evaluation of this case included ultrasonography (isoechoic mass in left ovary) and normal serum tumor marker levels. However, precise diagnosis requires histopathologic confirmation. Immunohistochemical markers are helpful in making the distinction between leiomyomas and fibromatous tumors. Desmin shows diffuse positivity in leiomyomas. Actin is positive in both leiomyomas and fibromas, but negative in thecomas [1]. Differential diagnosis includes other solitary tumors of the ovary (fibroma, thecoma, fibrothecoma, cellular fibroma, sclerosing stromal tumors, sex cord-stromal tumors), leiomyomas arising from broad ligament or uterus later becoming parasitic. Primary ovarian myoma should be inside the ovary without coexistent uterine myomas. However, this coexistence has been reported by many researchers [1]. The present patient had a hysterectomy 16 years previously. Although only some 70 cases have been reported, as a result of incidental findings, the authors believe some cases have gone unreported. Literature indicates that primary ovarian leiomyomas are a benign condition without recurrence, and oophorectomy is the preferred treatment, but in young women, fertility-sparing, minimally invasive procedures should be considered.

In conclusion, primary ovarian leiomyoma is a rare, benign tumor of the ovary. It should be considered in the differential diagnosis of solid tumors of the ovary.

Conflict of Interest: None declared.

Financial Disclosure: The authors declared that this study has received no financial support.

Authorship contributions: Concept - I.S., O.T.; Design H.A., O.T.; Supervision - O.T., I.S.; Materials - H.A., P.G.; Data collection and/or processing - F.V., I.S.; Analysis and/or interpretation - F.V., P.G.; Literature search - O.T.; Writing - F.V.; Critical review - I.S.

\section{REFERENCES}

1. Agrawal R, Kumar M, Agrawal L, Agrawal KK. A huge primary ovarian leiomyoma with degenerative changes-an unusual. J Clin Diagn Res 2013;7:1152-4. Crossre

2. Blue NR, Felix JC, Jaque J. Primary ovarian leiomyoma in a premenarchal adolescent: first reported case. J Pediatr Adolesc Gynecol 2014;27:87-8. Crossre.

3. Tomas D, Lenicek T, Tuckar N, Puljiz Z, Ledinsky M, Kruslin B. Primary ovarian leiomyoma associated with endometriotic cyst presenting with symptoms of acute appendicitis: a case report. Diagn Pathol 2009;4:25. Crossret

4. Khaffaf N, Khaffaf H, Wuketich S. Giant ovarian leiomyoma as a rare cause of acute abdomen and hydronephrosis. Obstet Gynecol 1996;87(5 Pt 2):872-3.

5. Erdemoglu E, Kamaci M, Bayram I, Güler A, Güler Sahin H. Primary giant leiomyoma of the ovary--case report. Eur J Gynaecol Oncol 2006;27:634-5.

6. Taskin MI, Ozturk E, Yildirim F, Ozdemir N, Inceboz U. Primary ovarian leiomyoma: A case report. Int J Surg Case Rep 2014;5:665-8. Crossret

7. Kawano Y, Takai N, Shimano M, Nasu K, Miyakawa I. Magnetic resonance imaging findings in leiomyoma of the ovary: a case report. Arch Gynecol Obstet 2006;273:298-300. Crossret

8. Güney M, Ozsoy M, Oral B, Mungan T, Kapucuoğlu N. Unilateral primary ovarian leiomyoma in adolescent: a case report. Arch Gynecol Obstet 2007;275:507-10. Crossre 